\title{
TOWARDS A BETTER UNDERSTANDING OF BEHAVIOUR OF BRIDGES WITH INTEGRAL ABUTMENTS
}

\author{
Martin Nilsson, Tech. Lic. \\ Luleå University of Technology \\ Luleå, Sweden \\ martin.a.nilsson@ltu.se \\ Jörgen Eriksen, PhD Student \\ Luleå University of Technology \\ Luleå, Sweden \\ jorgen.eriksen@Itu.se \\ Milan Veljkovic, Professor \\ Luleå University of Technology \\ Luleå, Sweden \\ milan.veljkovic@Itu.se
}

\begin{abstract}
One of issues that have not been completely resolved in bridges built without expansion joints is an influence of seasonal temperature variations and soil characteristics on the maximum bridge length.
\end{abstract}

A 40 meter long road composite bridge over river Leduån in the north of Sweden was built in 2005. The bridge superstructure was cast integrally with the substructure. One row of pile on each side of the bridge was constructed to support the abutment. The bridge was continually monitored 18 months in order to provide information on the strain level at the top of the pile as a function of the air temperature variations. The result from the measurements were compared to results obtained in 2D Finite Element Analysis. Soil characteristics were varied in the FEA to investigate its influence on the overall bridge behaviour as well as on the level of strain variations at the top of the piles.

The bridge monitoring was a part of a research project, INTAB, Economic and Durable Design of Composite Bridges with Integral Abutments, 2005-2008. The main objective of the project was to propose recommendations for rational analysis and design of bridges with integral abutments.

The total environmental impact and the life cycle costs of the integral abutment bridge were compared with a concrete bridge alternative for the same crossing.

\section{INTRODUCTION}

Integral abutment bridges are built without any expansion joints, and their benefits are the lower construction and maintenance costs. The abutments are generally supported on a single row of 
steel piles, to provide the required flexibility for accommodating the longitudinal bridge movements due to seasonal air temperature variations. Such movements impose cyclic displacements of the abutments, the back-fill and the steel piles. The magnitude of these cyclic displacements is a function of the level of the temperature variation, materials used in the superstructure and the length of the bridge.

The first bridges with integral abutments were built in the 1960's in the USA this type of bridge have in the recent years gained popularity in Europe, primarily in the UK and in the Scandinavian countries. Both the maximum span length and the total bridge length have increased through the years. The longest concrete bridge is $358 \mathrm{~m}$, and is located on Tennessee State Route 50 over Happy Hollow Creek. The longest steel girder integral bridge has a total length of $318 \mathrm{~m}$ and is located in Colorado [Hassiotis and Roman, 2005]. It is obvious that countries, such as the USA, with design requirements that are more open towards new technologies, encourage the implementation of innovative solutions even if they are not thoroughly examined. Although nationally accepted design specifications for integral bridges do not exist, each highway department is allowed to make decisions depending on their own expertise. It is interesting to note that some states in the USA allow plastic strains at the steel piles below the abutment back-walls.

The Leduån Bridge was designed for temperature range $80^{\circ} \mathrm{C}$, from $-40^{\circ} \mathrm{C}$ to $+40^{\circ} \mathrm{C}$. This rather large temperature differences certainly decreases the length limit compared to the experience from USA.

Only a few bridges with integral abutments have been built in Sweden since the 1980's, and the main obstacle for a wider acceptance of this type of bridge is the lack of recommendations for rational analysis and design. According to the Swedish code for bridges, BRO 2004 [Vägverket, 2004], no plastic strains are allowed at serviceability limit state even if the critical section is at the top of a pile. Such high strains may occur due to seasonal temperature variation a few times every year, and they are limited to a very narrow region.

The first investigation focusing on development of rational design for steel piles was initiated at LTU in the late 1990's and results were published in [Pétursson, 2004], [Tlustochowicz, 2007] [Hällmark, 2007] and [Nilsson, 2008].

\section{CONSTRUCTION OF THE BRIDGE OVER LEDUÅN RIVER}

In the end of 2005, it was decided to build an integral bridge on a road with low traffic. Therefore the bridge was seen as the perfect choice to monitor influence of the temperature variations.

The bridge was designed as a single span composite bridge with a span of $40 \mathrm{~m}$ and a concrete deck $5 \mathrm{~m}$ wide placed on the two steel girders, Fig.1.

Six vertical end bearing circular steel piles, with nominal dimensions $\varnothing 170 \times 10 \mathrm{~mm}$, were built to support each abutment. The very flexible abutment with the single row of piles was essential to allow for the longitudinal bridge movements. The surrounding soil is mainly silty fine sand to fine sandy silt. The abutments were designed with a shelf at the bottom. This made it possible for the piles to pass rather sheltered through the crushed stone used for erosion protection. The free distance between the piles and the concrete back-wall is nominally $80 \mathrm{~mm}$. Two meters of the piles below the bottom of the abutments were protected by sheltering steel pipes, $\varnothing 600 \mathrm{~mm}$, filled with loose sand. The piles were also wrapped with Styrofoam sheets where they passed through the sheltering pipes, see Fig. 2. 


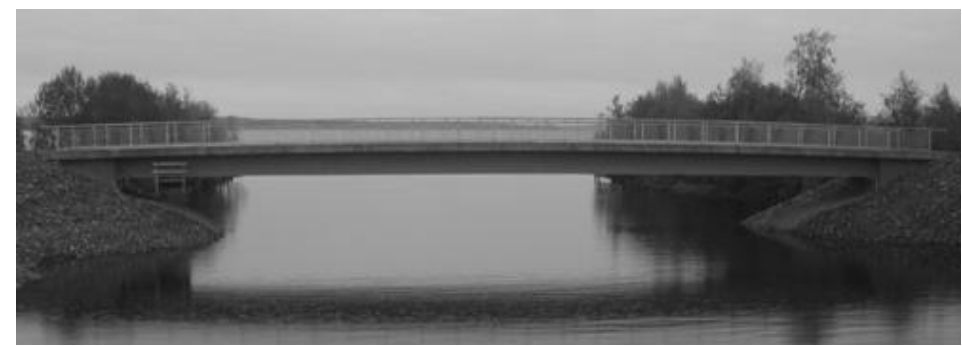

Fig. 1 - The Leduån Bridge

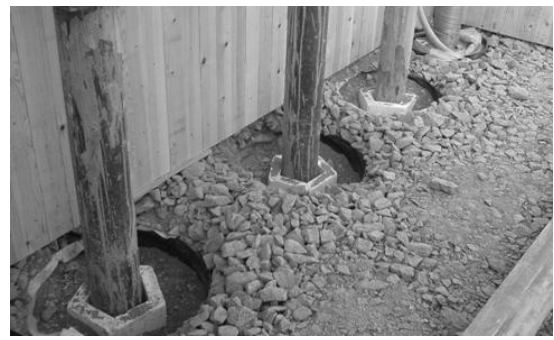

Fig. 2.- A part of the pile row

A conventional concrete bridge was considered as an alternative solution. Because of the construction technology this solution includes an internal support in the river. This fact influenced the total bridge price importantly. The cost estimation for the integral abutment bridge, based on Swedish prices showed that it was economically superior solution in comparison to the concrete bridge design. This cost estimation was made without taking into account the maintenance costs, which would have made the integral abutment bridge even more competitive.

The construction of the bridge with integral abutments was made in the following sequences:

- Excavation of the soil down to level $2 \mathrm{~m}$ below the back-wall.

- The tolerances for driving the $12 \mathrm{~m}$ long piles in the longitudinal direction were set to $\pm 100 \mathrm{~mm}$.

- The pile inclination and straightness were measured and approved by the bridge designer.

- Sheltering pipes, $\varnothing 600 \mathrm{~mm}$, were placed around the each pile, see Fig.2. Piles were wrapped with Styrofoam sheets and loose sand filled the space between.

- The lower part of the abutments back-walls was cast together with the wing walls, which were temporarily supported during casting.

- The temporary supports below the wing walls were removed, resulting in a pile moment in the opposite direction of the moments acting on the final structure. The moment from the wing walls can bee seen as a pre-stressing of the pile.

- Steel girders were placed on temporary bearings.

- Casting the bridge deck in the desired sequence excluding the abutment back-walls and the last portions of the bridge deck equal to the back-wall width. In this manner, all deadload slab rotations occurred prior to lock-up, and no dead-load moments were transferred to the supporting piles.

- Pouring the back-walls to full height. Since there was no back-filling at this point, the abutments were free to move without overcoming passive pressures against the backwalls.

- Pavement and rails were placed on the bridge.

\section{MONITORING PROGRAM}

To gain knowledge about the overall behaviour of the bridge, a total of 34 measurements were constantly recorded and stored, from the autumn of 2006 to the autumn 2007. Strain-gauges were welded to the bridge girders and to the piles, as shown in Fig. 3. Strains in the piles were 
measured at five different levels. At the upper four levels, called N1-N4 and S1-S4, the stored signal consists of the difference between two strain-gauges, to compensate for effect of the temperature variations. Signals obtained from both pairs of strain-gauges; at the fifth level, N5 and S5, were stored separately so the estimation of the axial forces in the piles was possible.

The movements of the abutments back-walls were measured with level indicators, position 6 and 7 , at each side of the bridge. The level indicators were placed in a vertical plane along the centre line of the bridge at a distance of $1,5 \mathrm{~m}$. The rotation and the displacement of the pile top were estimated from these measurements.

Two strain-gauges were welded at the steel girder, close to the south abutment, to get an indication of the constrained moment obtained at the bridge end. Strain-gauges were placed at the upper and lower flange, pos. 8 and 9 respectively.

Strain-gauges were also welded to the upper and lower flanges at the mid-span of the bridge, pos. 10 and 11, in order to estimate the overall bridge behaviour.

The air temperature as well as the temperatures at three positions of the bridge were measured; on the upper flange, on the lower flange and in the concrete, position 10, 11 and 12 respectively.

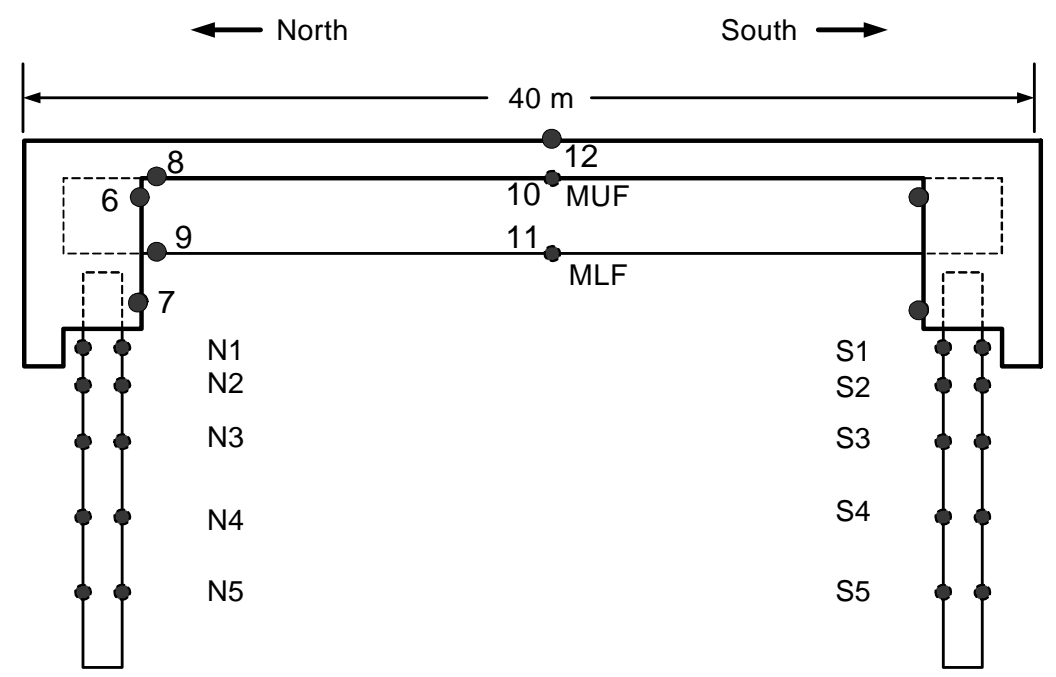

Fig. 3 - Position of long term monitoring gauges at the Leduån Bridge

\section{FE MODEL FOR AN EVALUATION THE PILE BEHAVIOUR}

FEA was used to interpret the results of the short term measurements. The short term measurements were done approximately every three months. The lorry with the maximum mass about $25 \mathrm{t}$ was used as the test load.

The soil characteristics was indirectly estimated calibrating results of a rather simple 2D FE model with the data measured in the short-term measurements. A limited geotechnical investigation was done in-site and used to check the credibility of FEA.

Pile were modelled using beam elements with elasto-plastic hardening material and von Mises yield criterion. The soil influence was modelled by elastic two node spring elements. The spring elements were connected to the pile nodes providing only horizontal support. Totally 69 springelements were used along the pile, distributed more densely at the pile top. The distance 
between the springs was in a range between $0.05 \mathrm{~m}$ to $0.15 \mathrm{~m}$. Every spring had a particular property allocated to produce a reaction force equivalent to a soil layer.

Recommendations from the Swedish bridge code BRO 2004 [Vägverket, 2004] were used as the starting value for the definition of the spring stiffness, Table 1.

The spring stiffness, $k$, is then:

$$
k=k_{\mathrm{k}} A_{\text {spring }}=k_{\mathrm{k}} d s
$$

Where $A_{\text {spring }}$ is the projected pile-soil contact area related to one spring, $d$ is the pile outer diameter, and $s$ the distance between two springs, $k_{\mathrm{k}}\left[\mathrm{MN} / \mathrm{m}^{3}\right]$ is the sub-grade reaction modulus at the depth $z$. For friction type soil the sub-grade reaction modulus is given by:

$$
k_{\mathrm{k}}=\frac{n_{\mathrm{h}} \mathrm{Z}}{d}
$$

The constant of sub-grade reaction modulus, $n_{\mathrm{h}}\left[\mathrm{MN} / \mathrm{m}^{3}\right]$, can be found in tables. According to the geotechnical investigation, the soil surrounding the piles was sand with a very low consistency. Thus $n_{\mathrm{h}}$ was taken as:

- $2,5 \mathrm{MN} / \mathrm{m}^{3}$ over the ground water level

- $1,5 \mathrm{MN} / \mathrm{m}^{3}$ under the ground water level

In the considered soil model, the soil stiffness increased linearly with the depth until a maximum value of the product $k_{\mathrm{k}} d$ was reached and it then remains constant.

For sand with a very low consistency, these limits were, $\left(k_{\mathrm{k}} d\right)_{\max }$ :

- $4,28 \mathrm{MN} / \mathrm{m}^{2}$ over the ground water level

- $2,57 \mathrm{MN} / \mathrm{m}^{2}$ under the ground water level

Calibration of FE model was done varying the characteristic of soil properties.

The ground water level was assumed to be at the top of the pile.

The depth at which the stiffness stops increasing and remains constant can be derived from $k_{\mathrm{k}} d$ and $n_{\mathrm{h}}$ :

$$
z_{\mathrm{c}}=\frac{k_{\mathrm{k}} d}{n_{\mathrm{h}}}=\frac{4,28}{2,5}=1,71 \mathrm{~m}
$$

and the corresponding stiffness was:

$$
k_{\mathrm{c}}=\left(k_{\mathrm{k}} d\right)_{\max } S
$$


Table 1 - Distribution of the soil properties along the pile, according to BRO 2004

\begin{tabular}{|l|l|l|}
\hline \multirow{2}{*}{$\begin{array}{l}\text { Below } \\
\text { ground water } \\
\text { Level }\end{array}$} & $\begin{array}{l}\text { Linear } \\
\text { increase } \\
0,00-1,71 \mathrm{~m}\end{array}$ & $n_{h d}=1,5 \frac{\mathrm{MN}}{\mathrm{m}^{3}}$ \\
\cline { 2 - 3 } & $\begin{array}{l}\text { Constant } \\
\text { stiffness } \\
1,71-6,00 \mathrm{~m}\end{array}$ & $k_{k} d=2,57 \frac{\mathrm{MN}}{\mathrm{m}^{2}}$ \\
\hline
\end{tabular}

Results of FE calculations with soil properties used for design according to BRO 2004 gave lower strains than those measured in-site. FEA indicated a higher curvature that must be due to a stronger lateral support of the pile from the surrounding soil. It is important to notice that the short term test-loading was performed in January 2007 as temperatures were very close to the minimal and the soil was probably frozen. It is know from [Kerokoski, 2006] that the soil stiffness may be increased approximately by a factor 30 compared to unfrozen soil below ground water level, see Fig.4.

For the northern pile the results of FEA fit the measurements best for a soil with a constant stiffness 20 to 30 times higher than that of the unfrozen soil below the ground water down to a depth of $2 \mathrm{~m}$. Below that level the characteristic soil according to BRO2004 was used. The behaviour of the southern pile was different. The soil parameters appeared to be higher only by a factor 5 to 10, see Fig.5.

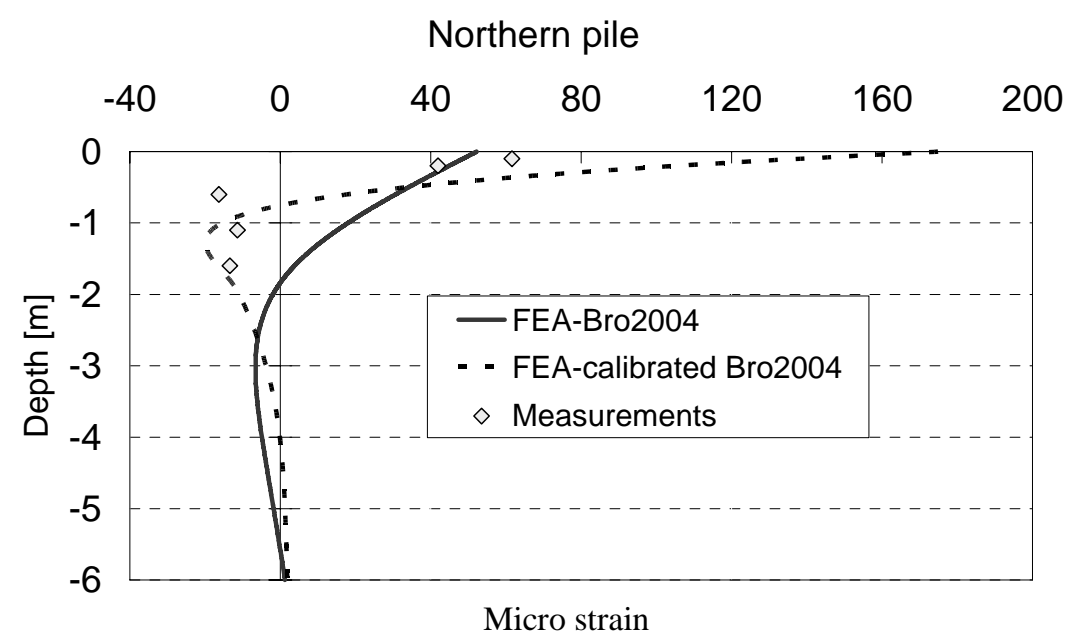

Fig. 4 - Calibration of the soil parameters by FEA 


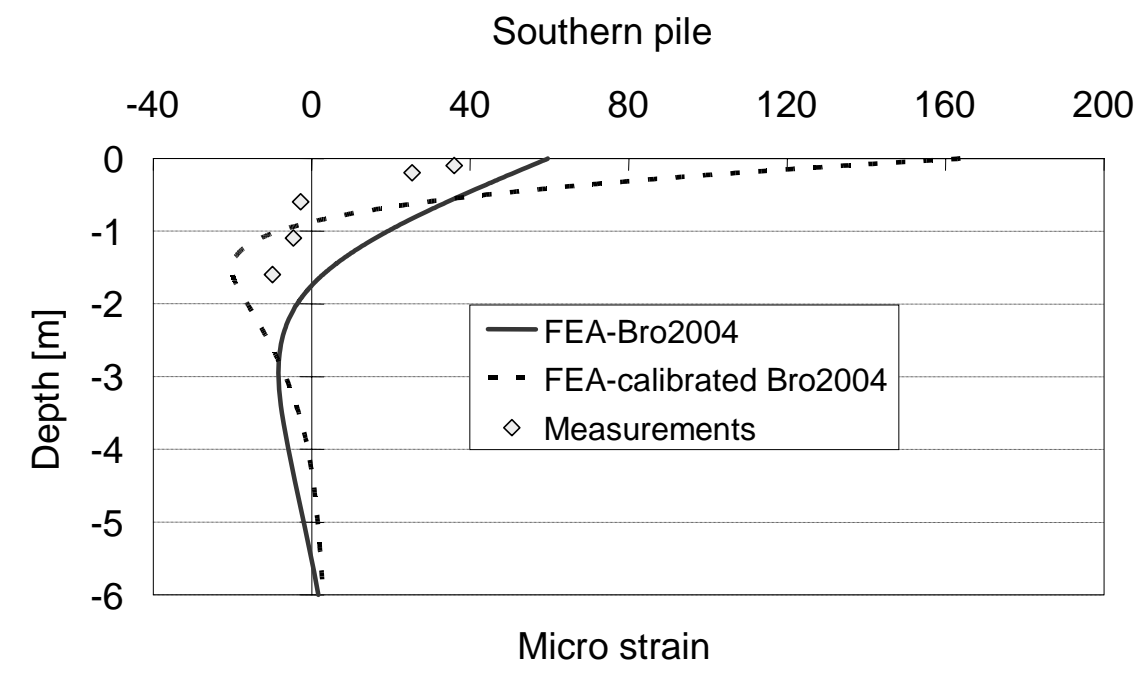

Fig. 5 - Calibration of the soil parameters by FEA

The influence of springs supporting the piles is almost negligible for the vertical displacement of the bridge measured while the empty lorry crossed the bridge, see Fig. 6.

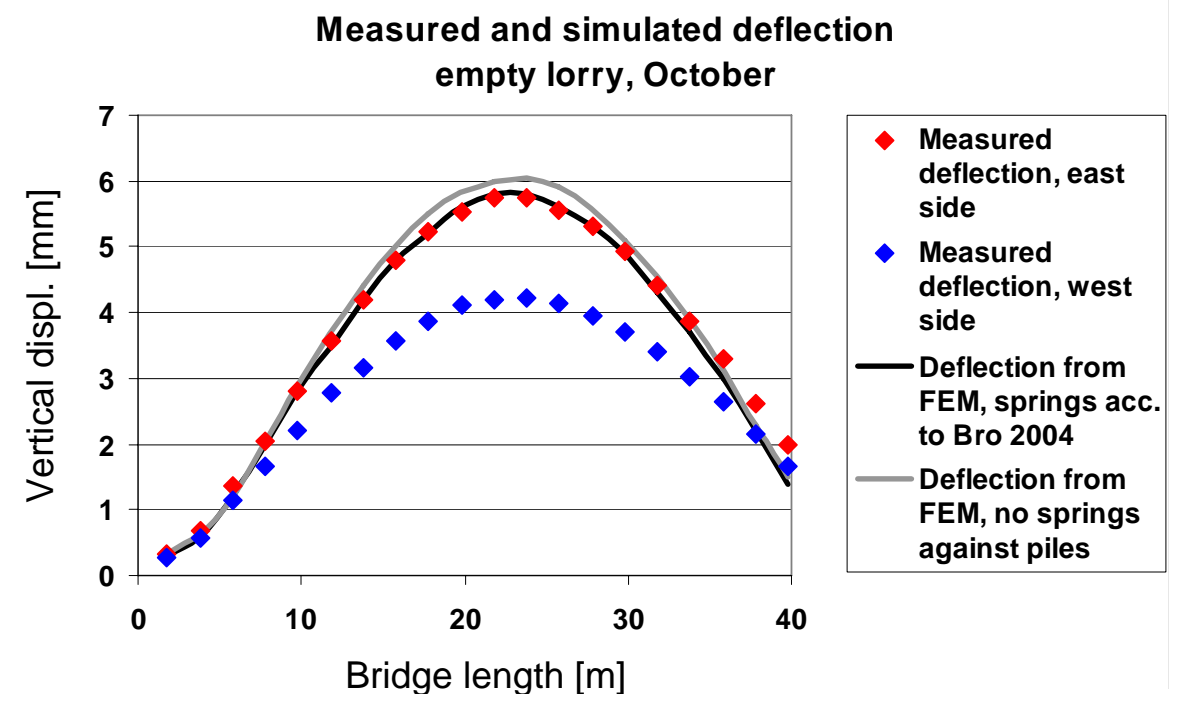

Fig. 6 - Measured deflection compared to deflection modelled by FEM the lorry mass $13,3 \mathrm{t}$ 


\section{RESULTS OF LONG TERM MEASUREMENTS}

In October 2007, one seasonal temperature cycle was completed.

Table 2 - Max measured movements of the end-screens, in 2007

\begin{tabular}{|l|l|l|l|c|c|}
\hline \multirow{2}{*}{ February 23 } & \multicolumn{2}{c|}{ July 7 } & $\begin{array}{c}\text { Total movement } \\
{[\mathrm{mm}]}\end{array}$ \\
\hline \multirow{2}{*}{ North side } & Upper gauge & 40,7 & Upper gauge & 34,9 & 5,8 \\
\cline { 2 - 6 } & Lower gauge & 41,6 & Lower gauge & 34,3 & 7,3 \\
\hline \multirow{2}{*}{ South side } & Upper gauge & 36,3 & Upper gauge & 31,9 & 4,4 \\
\cline { 2 - 6 } & Lower gauge & 36,8 & Lower gauge & 31,1 & 5,7 \\
\hline
\end{tabular}

Temperatures measured in the concrete in February 23 and July 7 , were $-17^{\circ} \mathrm{C}$ and $26{ }^{\circ} \mathrm{C}$, respectively. The total movement of the end-screen was $10,2 \mathrm{~mm}$ and $13 \mathrm{~mm}$ at the upper part and lower part, respectively. For the considered temperature difference, the theoretical movement of the bridge as the rigid body would be about $17 \mathrm{~mm}$.

Measured strains at the pile's level 1, at the north side are show in Fig.7. Strain peaks 576 microstrain and 305 microstrain were recorded in February and August, 2007, respectively. This difference led to the stress difference $185 \mathrm{MPa}$. The air temperature difference between these two datums was $37^{\circ} \mathrm{C}$ compared with $80^{\circ} \mathrm{C}$ which was used in design. The rate of the stress range vs. the temperature differences was $3,36 \frac{\mathrm{MPa}}{{ }^{\circ} \mathrm{C}}$ and $2,58 \frac{\mathrm{MPa}}{{ }^{\circ} \mathrm{C}}$ for the design and measured values, respectively.

\section{Measured strain difference \\ Level 1, north side}

18 October 2006 - 23 October 2007

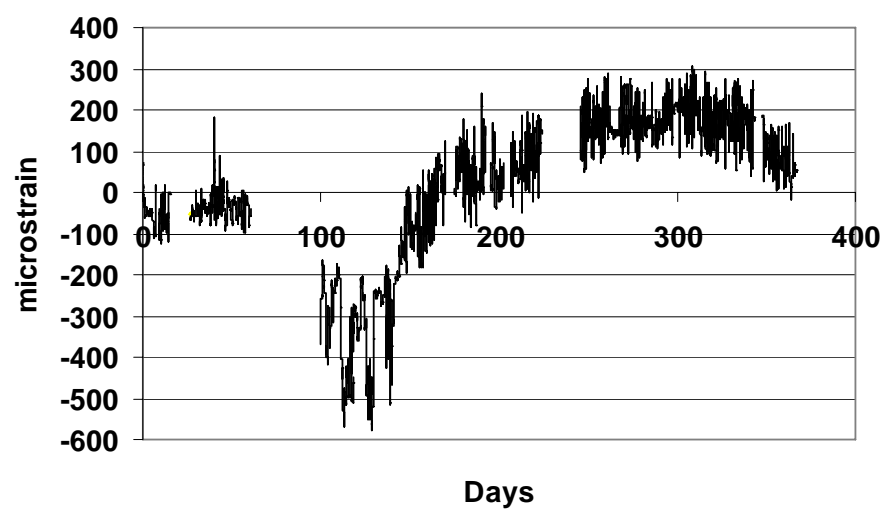

Fig. 7 - Measured strain difference at the top of the pile 


\section{LIFE CYCLE ANALYSIS}

The composite bridge with integral abutment was compared with an alternative solution, a reinforced concrete bridge with two spans of 18 meters, as published in [Gervásio 2008]. The concrete bridge had the middle pier in the river and end screens at the end supports.

The comparative analysis was based on a life cycle approach taking into consideration the estimated overall performance of both bridge solutions.

The initial costs for the concrete bridge in two spans would, according to the contractor, have exceeded the initial costs for the bridge with integral abutments with more than $50 \%$. The maintenance operations and costs were estimated and provided by the bridge inspectors at the Swedish National Road Administration, in order to create an appropriate life cycle for each bridge, see Table 3 and Table 4.

Table 3 - Maintenance plan of the composite bridge with integral abutments

\begin{tabular}{|l|c|c|c|c|}
\hline Maintenance activity & Unit Cost & Start year & End year & Frequency \\
\hline Inspection of the bridge & $320 €$ & 6 & 96 & 6 \\
\hline Painting of the steel structure & $37800 €$ & 30 & 90 & 30 \\
\hline Exchange of the edge beams & $51320 €$ & 30 & 90 & 30 \\
\hline
\end{tabular}

Table 4 - Maintenance plan of the reinforced concrete bridge

\begin{tabular}{|l|c|c|c|c|}
\hline Maintenance activity & Unit Cost & Start year & End year & Frequency \\
\hline Inspection of the bridge & $375 €$ & 6 & 96 & 6 \\
\hline Exchange of the edge beams & $60710 €$ & 30 & 90 & 30 \\
\hline Painting of bearings & $1260 €$ & 30 & 90 & 30 \\
\hline Expansion joints: & & & & \\
\hline Cleaning of joint & $100 €$ & 1 & 99 & 1 \\
\hline Exchange of rubber band & $2625 €$ & 10 & 90 & 10 \\
\hline Exchange of steel profile & $11025 €$ & 20 & 80 & 20 \\
\hline
\end{tabular}

The environmental Life Cycle Analysis (LCA) follows the guidelines of ISO standards for LCA [ISO14040], [ISO 14044] and it was performed according to the Eco-indicator methodology and using the SimaPro software [PRé Consultants, 2008]. The object of assessment, the functional unit, was a bridge designed for a service life of 120 years.

For each process included in the LCA, it was necessary to quantify all input flows (materials, energy, etc) and output flows (emissions to air, water, soil; waste; etc). Data for construction materials, apart from the steel, and transportation were obtained from the Ecoinvent database, which was included in SimaPro software. Data for the production of steel was obtained from the IISI database. 
The normalized results of the life cycle analysis were shown in Fig.8, using three damage categories for each structural solution. In each column the results obtained for each life cycle stage were summed up. According to Fig.8, the composite bridge had a better environmental performance in every damage category.

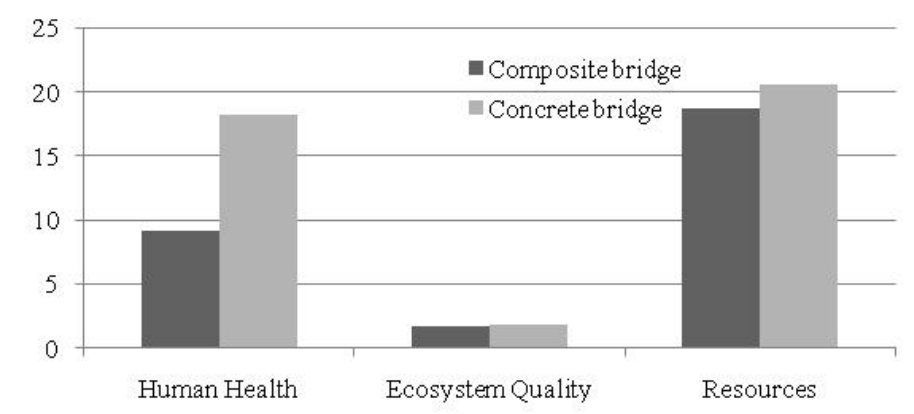

Fig. 8 - Total damage analysis per bridge solution

The same results were represented in Fig. 9 but according to the respective life cycle stage and for each structural solution. In each column the normalized results obtained for each damage category were summed up.

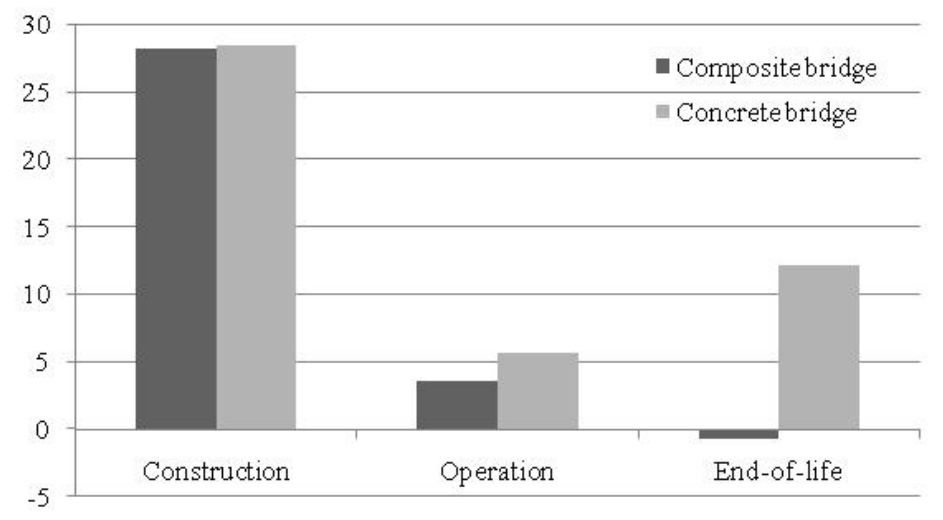

Fig. 9- Damage analysis per life cycle stage

It can also be concluded that the construction stage has a major influence on the final result of the analysis. The end-of-life stage was important, particularly in the case of recyclable materials. In this case study the operation stage was not significant as many simplifications were assumed due to lack of data.

\section{CONCLUSIONS}

The results obtained from the monitoring of the Leduån Bridge indicated that a rather simple FE model which was suitable for design practice may be used to calibrate the soil characteristics.

Results from the measurements, obtained in January 2007, showed that the stiffness of the frozen soil was 10 to 20 times stronger than the stiffness of unfrozen soil. 
The measured strain range caused by the air temperature variations during the period of the monitoring was approximately 900 microstrain, which corresponds to $95 \mathrm{MPa}$ on each side of the pile. Such strain amplitude due to seasonal temperature variation can not cause serviceability problems and the piles are properly designed for fatigue endurance.

Results of measurements and FEA indicated a very positive role of loose sand and styrofoam around the piles. This solution allows larger displacement of the pile which reduces the strains. In some states in the USA it is demanded to supply integral bridges with this type of solution.

A comparative analysis between the integral composite bridge and the concrete bridge with expansion joints showed that due to the minimization of maintenance operations, the integral bridge has the most economical solution, both in terms of costs for the agency and costs for the users. From the environmental perspective the composite bridge with integral abutment had advantage compared to the concrete solution, mainly due to the recycling of steel.

\section{ACKNOWLEDGEMENTS}

Financial support obtained from the Research found for Steel and Coal (RFS-PR-04120) and from Development Fund of the Swedish Construction Industry (SBUF-11708) is gratefully acknowledged. Many thanks to Prof. Peter Collin and Tech.Lic. Hans Pétursson at Ramböll, Sweden for the discussion related to the structural issues. Mrs. Helena Gervásio and Prof. Luis Simões da Silva, Coimbra University, Portugal had significantly contributed to the LCA which was much appreciated.

\section{REFERENCES}

Gervásio, G., Eriksen, J., Veljkovic, M., Simões da Silva, L., Comparative life cycle analysis of an integral abutment bridge and a concrete bridge with expansion joints, $7^{\text {th }}$ International Conference on Steel Bridges, Guimarães, Portugal, 2008

Hassiotis, A.S., and Roman, E.K. Survey of current issues on the use of integral abutment bridges, Bridge Structures, Vol. 1, No. 2, June 2005, 81 - 101

Hällmark R., Low-cycle fatigue of steel piles in integral abutment bridges, Master Thesis, 2006:291 CIV, Luleå University of Technology, http://epubl.Itu.se/1402-1617/2006/291/LTU-EX06291-SE.pdf

ISO 14040. "Environmental management - life cycle assessment - Principles and framework", International Organization for Standardization, Geneva, Switzerland, 2006

ISO 14044. "Environmental management - life cycle assessment - Requirements and guidelines", International Organization for Standardization, Geneva, Switzerland, 2006

Kerokoski, O.; Sillan ja maan yhteistoiminta: liikuntasaumattomiensiltojen laskennallinen tarkastelu. Tampereen teknillinen yliopisto, Maa- ja pohjarakenteiden laitos, tutkimusraportti 70, Tampere. 2006

Nilsson, Martin, Evaluation of in-situ measurements of composite bridge with integral abutments, Licentiate thesis (2008) , http://epubl.Itu.se/1402-1757/2008/02/LTU-LIC-0802SE.pdf

Pétursson Hans, Broar med integrerade landfästen, Licentiate thesis, in Swedish, (2000) ISSN: 1402-1757 
PRé Consultants, SimaPro 7. "Software and database manual", Amersfoort, The Netherlands, 2008

Tlustochowicz, G., Optimized design of Integral Abutments for a Three Span Composite Bridge, Master Thesis, 2005:248 CIV, Luleå University of Technology, http://epubl.Itu.se/14021617/2005/248/LTU-EX-05248-SE.pdf

Vägverket, Swedish code for bridges, BRO 2004, The Swedish National Road Administration, in Swedish, http://www.vv.se/templates/page3 7900.aspx. 